\title{
Endocrine Surgery Without the Bells and Whistles: Editorial of the International Association of Endocrine Surgeons Symposium
}

\author{
Janice L. Pasieka ${ }^{1}$
}

Published online: 20 November 2019

(c) Société Internationale de Chirurgie 2019

At the recent scientific meeting of the International Association of Endocrine Surgeons (IAES), in Krakow Poland, the IAES held a symposium on endocrine surgery without the 'high-tech' adjuncts and surgical instruments that many of us in the developed world have access to. The initial concept was to illustrate that endocrine surgery could still be done in lower-income countries that do not have access to expensive technologies such as robotics, energy devices, endoscopic equipment, nuclear medicine and intra-operative parathyroid hormone (iPTH). It became apparent, however, that this symposium was of value to all endocrine surgeons. Many institutions and countries have recognized the need for cost containment in the field of healthcare, and as such, not just lower-income nations have limited availability to these tools.

Yeung's summary on parathyroid surgery illustrated that the gold standard of a four-gland parathyroid exploration can be safely and effectively done without the use of preoperative localization studies or iPTH. It is not these adjuncts, but a comprehensive understanding of parathyroid embryology and anatomy that provides the foundation for successful parathyroid surgery. Miller's summary on adrenal surgery highlighted that even in today's world where endoscopic/laparoscopic adrenalectomy is the treatment of choice for most adrenal lesions, there are still indications for an open adrenalectomy. It is clear that all adrenal surgeons must also have in their armamentarium the ability to do open adrealectomies.

As technology continues to evolve and improve our surgical craft, we must remember that many of these tools are merely adjuncts for us to utilize and apply appropriately within our healthcare environment. Cost containment may prohibit the utilization of high-tech instruments and adjuncts regardless of where one practices. Getting back to basic, safe surgery is a necessity to good patient care. This IAES symposium clearly illustrated the need to include in our teaching curriculum, basic surgical principals without the luxury of advanced technology to ensure that the next generation of endocrine surgeons has the ability to practice safely and effectively in their future healthcare environment.

Publisher's Note Springer Nature remains neutral with regard to jurisdictional claims in published maps and institutional affiliations.

Janice L. Pasieka

Janice.pasieka@ahs.ca

1 Department of Surgery and Oncology, Foothills Medical Center, Section General Surgery, Cumming's School of Medicine, University of Calgary, Calgary, AB, Canada 